\title{
Use of high kilovoltage filtered beam radiographs for detection of bronchial situs in infants and young children
}

\author{
JOHN E DEANFIELD, RANJIT LEANAGE, „ JOHN STROOBANT, \\ ALAN R CHRISPIN, JAMES F N TAYLOR, FERGUS J MACARTNEY†
}

From the Thoracic Unit, The Hospital for Sick Children, Great Ormond Street, London

SUMMARY Determination of atrial situs is of cardinal importance in the analysis of complex congenital heart lesions, and is best predicted from bronchial situs. Previous methods for assessing bronchial morphology, however, are unsuited to the very young patient.

To assess bronchial morphology, 100 consecutive patients under 18 months of age (median 57.5 days) with suspected congenital heart disease were studied by high kilovoltage filtered beam radiographs, before cardiac catheterisation. This low radiation dose technique clearly defined bronchial anatomy in 95 patients. The lengths of the left and right main bronchi were compared and 10 cases $(10 \%)$ had a ratio less than 1.5 suggesting bronchial isomerism. Discriminant function analysis based on tracheal width and bronchial length enabled clear distinction of right from left bronchi. Four patients had bilateral right and six had bilateral left bronchi. Four of these 10 cases died and had necropsy confirmation of the radiological diagnosis.

Practical prediction about cardiac anatomy, particularly the systemic and pulmonary venous return, may be made when bronchial morphology is known.

The reliable identification of atrial situs is of fundamental importance in the classification of congenital heart disease. The classical method of predicting atrial situs has been to ascertain the position of the abdominal viscera. This method is unreliable when applied to cases with visceral heterotaxy. ${ }^{1-3}$ Numerous series have shown a significant association between abnormalities of splenic development (asplenia and polysplenia syndromes) and visceral heterotaxy. ${ }^{4-11}$ The use of criteria which suggest asplenia, however, such as the presence of Howell-Jolly bodies in the blood, does not greatly improve correct prediction of atrial situs, ${ }^{12}$ and is inapplicable in the newborn. Van Mierop et al..$^{13}$ first reported the use of penetrated chest radiography to assess bronchial situs and hence atrial situs. Subsequent necropsy evidence has shown that bronchial situs is the most reliable indirect method of predicting atrial situs. ${ }^{8} 91214$ Bronchial situs can be reliably and

$\star \mathrm{RL}$ is a British Heart Foundation Junior Research Fellow.

† FJM is supported by the Vandervell and British Heart Foundations.

Received for publication 15 May 1980 objectively established in life with the use of bronchial tomography. ${ }^{15}$ That technique, however, is not easily applied to very young patients, whereas it is in this group that the highest incidence of abnormal atrial situs would be expected.

The present study was designed to see whether bronchial morphology could be determined simply and reliably by high kilovoltage filtered beam radiography in this age group; whether, in practice, the separate entities of bilateral right bronchi (right isomerism) and bilateral left bronchi (left isomerism) could be distinguished in cases of situs ambiguus, and what value the investigation had as a screening technique.

\section{Subjects and methods}

High kilovoltage filtered beam radiographs were performed in 100 consecutive patients, under 18 months of age, who presented to The Hospital for Sick Children, Great Ormond Street, with congenital heart disease, over a six-month period. Ninety-one of these patients were under 1 year old and the median age was 57.5 days. Both emergency 
and routine admissions were included in the study, and all patients underwent cardiac catheterisation.

\section{$x$-RAY TECHNIQUE}

The patient was placed face upward on a horizontal Bucky table. The field of interest was a projection of the thorax from above the clavicles to the lower sternum and this field was defined by using the light beam collimator. The $x$-ray beam first passes through a $2 \mathrm{~mm}$ layer of aluminium incorporated into the tube housing and collimator box; it then passes through a filter consisting of $0.5 \mathrm{~mm}$ of copper and $0.4 \mathrm{~mm}$ of tin inserted into the collimator box with the copper layer on the side of the $x$-ray tube. ${ }^{16-18} A$ very light grid $\star$ was retained to absorb radiation scattered forward. Kilovoltage settings in the range 125 to 140 were used on a three-phase generator. The milli-ampere-seconds were fixed and the kilovoltage setting varied according to patient size. Kodak Ortho $\mathrm{G}$ film was used in combination with $3 \mathrm{M}$ Alpha 8 speed intensifying screens.

On the exposed radiograph, bone detail is effaced to a considerable degree allowing soft tissue and gas interfaces in the mediastinum and adjacent lung to be seen. Thus the trachea, bronchi, aortic arch, and pulmonary artery conus may be identified. In addition, the lower margin of a normally located left atrium may be visible and the ordinarily dense thymic shadow is seen as a structure of lesser density than the main blood-containing vascular pathways. The calibre of the proximal pulmonary blood vessels near the lung hilum could often be estimated subjectively. The principal concern of this study, however, was the ability to demonstrate the tracheal and proximal bronchial anatomy. The latter was assessed independently by two of the authors (FJM, ARC), and the length of the left and right main bronchi was measured using the technique described by Partridge et al. ${ }^{15}$ and shown in Fig. 1. To standardise the varying bronchial lengths for each child, the tracheal width at the level of the clavicles was measured. This variable was chosen on empirical grounds because, at this level, the trachea is just outside the thorax, not subject to changes in intrathoracic pressure, and is presumably related to the size of the child. Further, it is magnified to the same degree as the bronchi, so that calculation of the magnification factor is unnecessary.

In all cases, the position of the heart in the chest and the side of the aortic arch in relation to the trachea were recorded from the filter beam radiograph. The frontal $P$ wave axis was measured from the electrocardiogram. In the patients who had

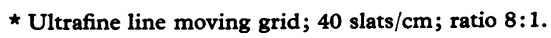

isomeric bronchi shown by the filter beam radiographs, the bronchial morphology was checked by observation of the relation of the pulmonary arteries to the tracheobronchial tree in a lateral angiocardiogram, as advocated by Soto and colleagues. ${ }^{19}$

Cardiac catheterisation and angiocardiography were performed to show the precise cardiac anomaly: the presence of bilateral superior vena cavae was sought by contrast injection into the innominate vein, and the course of the inferior vena cava noted. Interruption of the inferior vena cava was diagnosed where the catheter could not be passed directly from the abdominal inferior vena cava to an atrium, but entered the heart via an azygos system on one side or the other. Pulmonary venous drainage was identified by direct catheterisation or on the pulmonary venous phase of a right ventricular or pulmonary artery angiocardiogram. Where the patient underwent cardiac surgery or necropsy, confirmation of the radiological prediction of atrial and bronchial morphology was sought. Necropsies were performed in nine cases.

Statistical analyses of the findings were carried out using the Statistical package for the social sciences, ${ }^{20}$ together with a brief Fortran IV program to organise data entry.

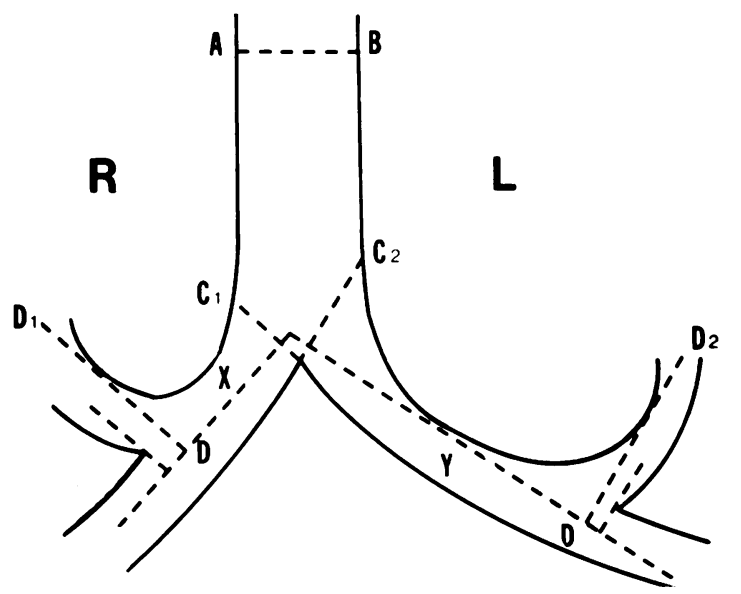

Fig. 1 Measurement of bronchial length. The mean axes of the main bronchi are first drawn and perpendicular lines to these axes are drawn from the carina. Further perpendicular lines are drawn either tangential to the proximal upper lobe bronchial wall or at the angle of the distal wall with the main bronchus. One of these two lines could always be drawn. The bronchial lengths are then distances between $C_{1}$ and $D_{1}(X)$ and $C_{2}$ and $D_{2}(Y)$. The tracheal width $(A B)$ was measured at the level of the clavicles (see text). 


\section{Results}

The high kilovoltage filtered beam radiographs enabled clear definition of bronchial anatomy in 95 patients (Fig. 2 to 4 ). In five cases the radiographs were not of diagnostic quality as both main bronchi could not be seen to their first division: these cases occurred early in the series when we were less familiar with the technique.

The lengths of the main bronchi to the left and right lungs were compared and the ratios of the bronchial lengths are shown in Fig. 5. Eighty-five patients had a ratio above 1.5 , implying situs solitus. $^{12}$ Ten patients were clearly different, having a ratio below 1.5 , which is diagnostic of bronchial isomerism. ${ }^{12}$ Simple examination of the radiographs without any measurements by two of the authors, working independently, proved reliable in differentiating patients with bronchial isomerism

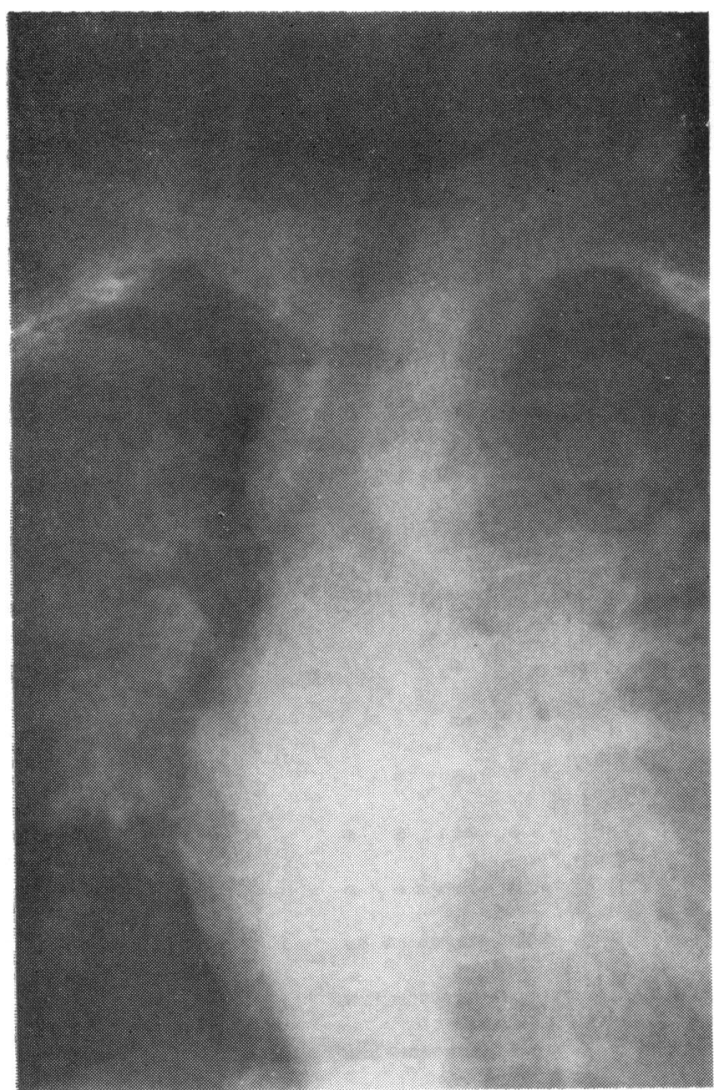

Fig. 2 Filter beam radiograph showing situs solitus. There is a short bronchus on the right which bifurcates early and a longer curved bronchus on the left.

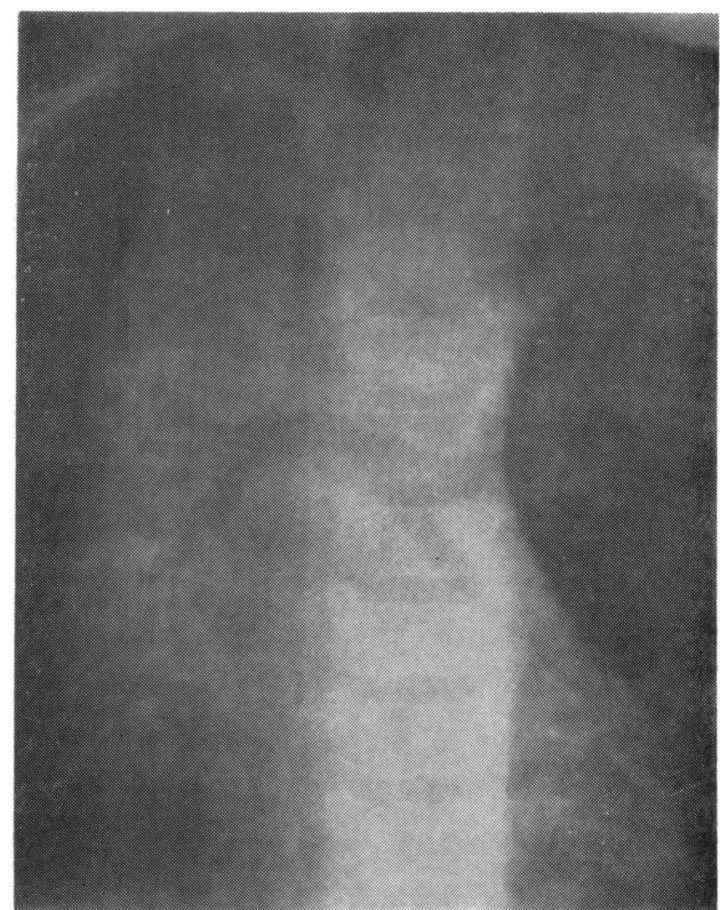

Fig. 3 Filter beam radiograph showing right isomerism with two short early branching bronchi.

from those with situs solitus. It was not possible, however, to distinguish left from right isomerism with certainty without measuring bronchial lengths. In order to make this distinction, the lengths of the left and right main bronchi in the patients with situs solitus (that is those with bronchial ratios above 1.5) were plotted against tracheal width (Fig. 6). Using discriminant function analysis, a linear discriminant equation was calculated based on bronchial length and tracheal width, entry of both of which into the equation was highly significant $(p<0.0005)$. Where $b=$ bronchial length $(\mathrm{mm})$ and $\mathrm{t}=$ tracheal width $(\mathrm{mm})$ the discriminant function was

$$
0 \cdot 292 b-0.492 t-2 \cdot 85
$$

When this function is positive the bronchus is classified as left and when negative as right: the morphology of any bronchus can easily be identified by referring to Fig. 6 . The 10 patients with bronchial isomerism could be divided into two groups: six patients with bilateral left bronchi (left isomerism) and four with bilateral right bronchi (right isomerism). The clinical data of these patients are shown in the Table. 


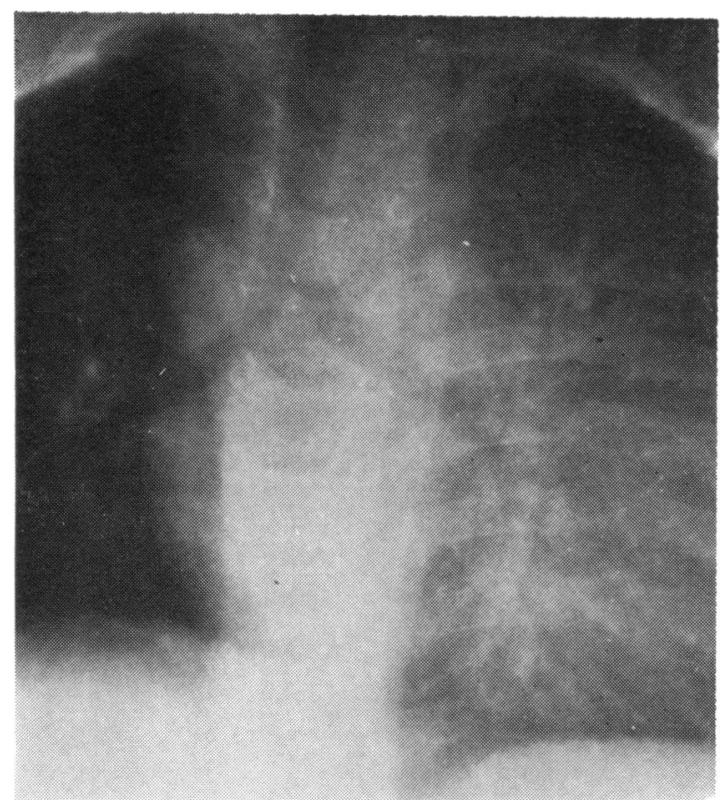

Fig. 4 Left isomerism with two long curved bronchi. An azygos continuation of the inferior vena cava is clearly seen on the patient's right side.

\section{LEFT ISOMERISM (six patients)}

One patient with a ventricular septal defect died and at necropsy the presence of bilateral left atria and hyparterial bronchi was confirmed. Of the remaining five patients, three had isolated ventricular septal defects, one tetralogy of Fallot, and one a univentricular heart of left ventricular type with pulmonary stenosis. Interruption of the inferior vena cava was found in two patients $(33 \%)$, and a superiorly orientated $\mathrm{p}$ wave axis on the electrocardiogram in one patient $(17 \%)$. The pulmonary venous drainage was normal in all six cases. No attempt was made to confirm or exclude the presence of polysplenia.

\section{RIGHT ISOMERISM (four patients)}

Three of the four patients had univentricular hearts, with pulmonary atresia in two $(50 \%)$ and pulmonary stenosis in a third. The pulmonary venous drainage was anomalous in these three patients $(75 \%)$; it was infradiaphragmatic in two and supradiaphragmatic in the third. All three patients died. At necropsy right isomerism of the atria and bronchi was confirmed, and no spleen was found.

No case of bronchial situs inversus was found in the series.

\section{Discussion}

The technique of high kilovoltage filter beam radiography enables reliable, high quality visualisation of bronchial anatomy in a very young patient, where breathing blur limits the usefulness of bronchial tomography. ${ }^{15}$ This is accomplished with a low radiation dose (probably about one-sixth that of a routine chest radiograph when calcium tungstate intensifying screens are used) and can easily be performed as part of the initial examination. The lengths of the left and right main bronchi
Fig. 5 Distribution of bronchial length ratios (left to right bronchial ratio).

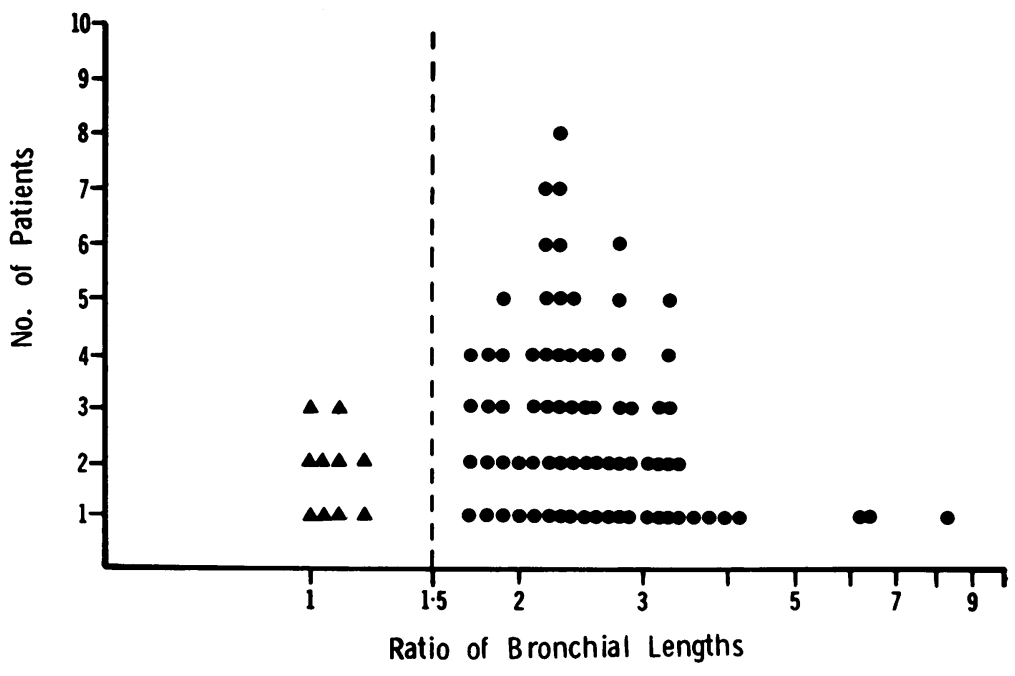




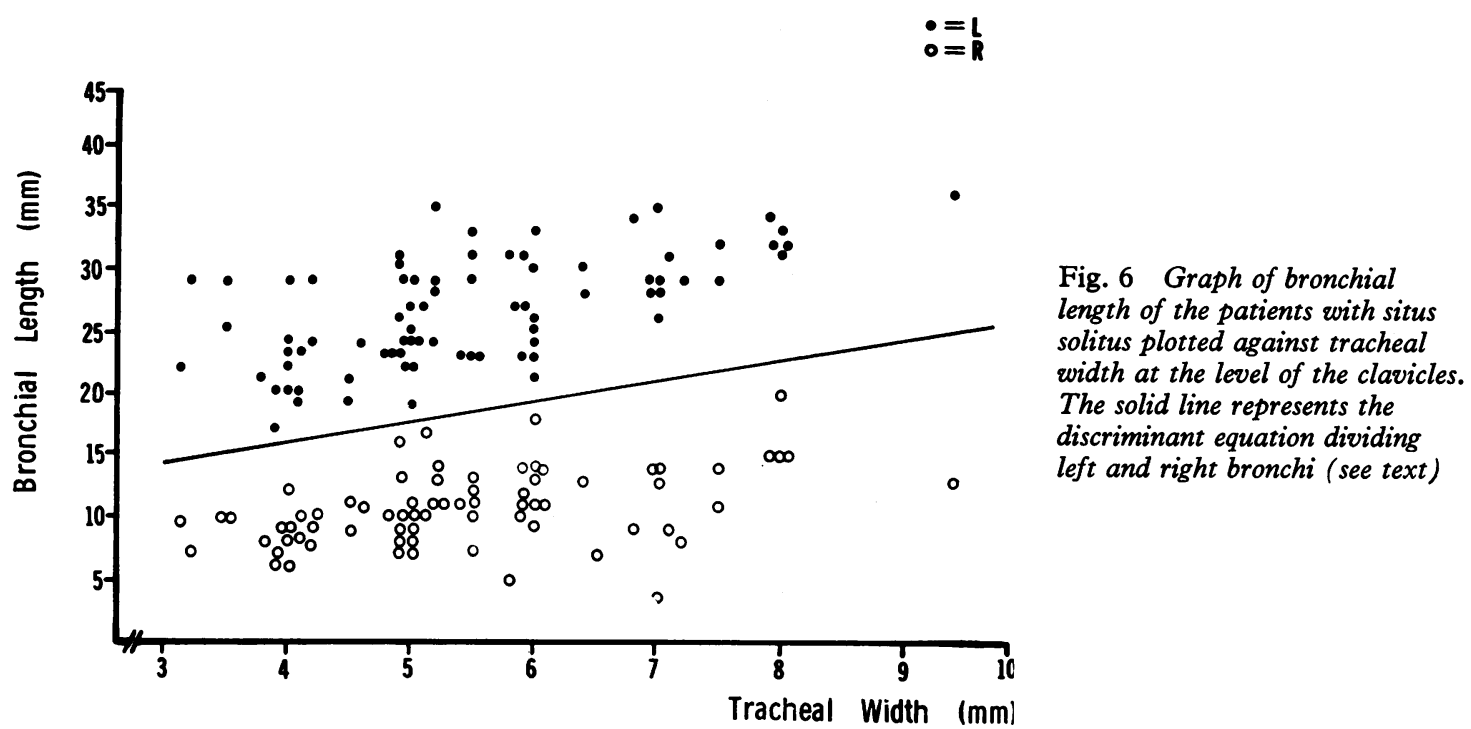

are measured and bronchial isomerism is diagnosed when the ratio of bronchial length is less than 1.5: this can be done without any knowledge of the magnification factors of the equipment. If the ratio 1s above 1.5 , the longer bronchus is morphologically left, and the short bronchus morphologically right. To classify unknown isomeric bronchi into left or right morphology one need only measure tracheal width and refer to Fig. 6. No complex calculations are required.

Bronchial morphology is important because of its relation to atrial morphology. The method of sequential chamber localisation introduced by Van Praagh $^{21} 22$ to classify congenital heart disease is based on the identification of atrial situs. While ventricular morphology and great vessel anatomy are easily diagnosed by angiocardiography, direct identification of atrial morphology is more difficult and requires selective atrial appendage injections of contrast medium. This method has yet to be validated in a large series of patients and is impracticable precisely when it is most needed. Patients with atrial isomerism frequently have exceedingly complex cardiac anatomies, and three selective injections into ventricles or great arteries are often required to demonstrate the ventricular and great artery anatomy. Thus, if contrast medium toxicity is to be avoided, an indirect but reliable method of identifying atrial situs is necessary. Bronchial isomerism was noted in patients with visceral

Table Data of cases with bronchial isomerism

\begin{tabular}{|c|c|c|c|c|c|c|c|c|c|c|c|}
\hline \multirow{2}{*}{$\begin{array}{l}\text { Case } \\
\text { no. }\end{array}$} & \multirow{2}{*}{$\begin{array}{l}\text { Age } \\
(w)\end{array}$} & \multirow[t]{2}{*}{ Sex } & \multirow{2}{*}{$\begin{array}{l}\text { Position of } \\
\text { cardiac } \\
\text { apex }\end{array}$} & \multirow{2}{*}{$\begin{array}{l}\text { Aortic } \\
\text { arch }\end{array}$} & \multirow[t]{2}{*}{$I V C$} & \multirow{2}{*}{$\begin{array}{l}P \text { wave } \\
\text { axis }\end{array}$} & \multicolumn{2}{|c|}{$\begin{array}{l}\text { Bronchial } \\
\text { lengths ( } \mathrm{mm} \text { ) }\end{array}$} & \multirow{2}{*}{$\begin{array}{l}\text { Ratio of } \\
\text { lengths }\end{array}$} & \multirow{2}{*}{$\begin{array}{l}\text { Thoracic } \\
\text { situs }\end{array}$} & \multirow{2}{*}{ Diagnosis } \\
\hline & & & & & & & $L$ & $\boldsymbol{R}$ & & & \\
\hline $\begin{array}{r}1 \\
2 \\
3 \\
4 \\
5 \\
6 \\
7 \\
8 \\
9 \\
10\end{array}$ & $\begin{array}{c}8 \\
48 \\
4 \\
44 \\
4 \\
2 \\
5 \\
0 \cdot 3 \\
0 \cdot 14 \\
1\end{array}$ & $\begin{array}{l}\mathbf{F} \\
\mathbf{F} \\
\mathbf{M} \\
\mathbf{M} \\
\mathbf{F} \\
\mathbf{M} \\
\mathbf{F} \\
\mathbf{M} \\
\mathbf{F} \\
\mathrm{F}\end{array}$ & $\begin{array}{l}\text { L } \\
\text { L } \\
\text { L } \\
\text { L } \\
\text { L } \\
\mathbf{L} \\
\mathbf{L} \\
\mathbf{R} \\
\mathbf{L} \\
\mathbf{L}\end{array}$ & $\begin{array}{l}\mathbf{L} \\
\mathbf{L} \\
\mathbf{L} \\
\mathbf{L} \\
\mathbf{R} \\
\mathbf{L} \\
\mathbf{R} \\
\mathbf{R} \\
\mathbf{L} \\
\mathbf{R}\end{array}$ & $\begin{array}{l}\mathbf{R} \\
\text { Int } \\
\text { Int } \\
\mathbf{R} \\
\mathbf{R} \\
\mathbf{R} \\
\mathbf{R} \\
\mathbf{L} \\
\mathbf{R} \\
\mathbf{R}\end{array}$ & $\begin{array}{l}+90 \\
+60 \\
-60 \\
+60 \\
+45 \\
+105 \\
+30 \\
+60 \\
+60 \\
+90\end{array}$ & $\begin{array}{r}28 \\
30 \\
28 \\
22 \\
17 \\
20 \\
11 \\
11 \\
13 \\
8\end{array}$ & $\begin{array}{r}27 \\
25 \\
28 \\
26 \\
18 \\
22 \\
12 \\
11 \\
12 \\
8\end{array}$ & $\begin{array}{l}1 \cdot 04 \\
1 \cdot 2 \\
1 \cdot 0 \\
1 \cdot 23 \\
1.06 \\
1 \cdot 1 \\
1 \cdot 09 \\
1 \cdot 0 \\
1 \cdot 1 \\
1 \cdot 0\end{array}$ & $\begin{array}{l}\mathbf{L} \\
\mathbf{L} \\
\mathbf{L} \\
\mathbf{L} \\
\mathbf{L} \\
\mathbf{L} \\
\mathbf{R} \\
\mathbf{R} \\
\mathbf{R} \\
\mathbf{R}\end{array}$ & 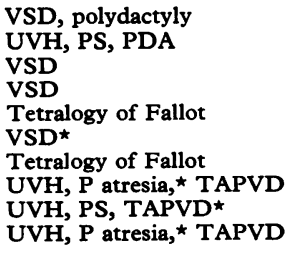 \\
\hline
\end{tabular}

Abbreviations: IVC, inferior vena cava; L, left; R, right; Int, interrupted; VSD, ventricular septal defect; PS, pulmonary stenosis;

PDA, persistent ductus arteriosus; UVH, univentricular heart; TAPVD, total anomalous pulmonary venous drainage.

$\star$ Diagnosis confirmed at necropsy. 
heterotaxy in 1926 by Pernkopf ${ }^{23}$ and the close relation between bronchial and atrial situs was observed by later investigators. ${ }^{7142425}$ There are some reports where bronchial situs predicted atrial situs incorrectly ${ }^{26}{ }^{27}$ but in a review of 45 necropsy cases with atrial isomerism, Macartney and colleagues ${ }^{28}$ found that atrial situs and thoracic (or bronchial) situs corresponded in all cases. We consider that it is more appropriate to use atrial situs than splenic status to categorise congenital heart lesions. Right atrial isomerism is not always associated with asplenia nor left atrial isomerism with polysplenia. ${ }^{28}$ Establishing splenic status in life is difficult, whereas establishing thoracic situs is easy using filter beam radiographs. Such radiographs avoid the technical problems inherent in bronchial tomography in infants. This present study was limited to infants and toddlers, but our experience of the technique applied to older children with suspected anomalies of situs suggests that image quality is as good as that obtained with standard tomography.

We found a high incidence $(10 \%)$ of bronchial isomerism among our 100 cases of congenital heart disease below the age of 18 months, and subsequent experience with the technique has confirmed this finding. Indeed it is in these very young patients that the highest incidence of situs ambiguus would be expected, for the associated cardiac lesions often carry a poor prognosis. We have no means of comparing our results with those of other centres as there are no previously reported series of in vivo determination of atrial situs in this age group.

The early identification of atrial situs has a distinct practical advantage and is not only of value in the correct description of complex congenital heart defects. Using filter beam radiographs one can distinguish left isomerism from right isomerism, and this enables several important predictions to be made about the cardiac anatomy. Left isomerism is associated among other lesions with interruption of the inferior vena cava (as found in one-third of our patients), so one should think carefully before deciding to catheterise such patients from the leg. Patients with right isomerism have a high incidence of univentricular heart, ventricular septal defect, and pulmonary stenosis or atresia. In right isomerism, total anomalous pulmonary venous return is frequent $(75 \%$ of our patients), and it is important to be prepared for this possibility before cardiac catheterisation. If, because of low pulmonary blood flow, the amount of oxygenated blood returning to the systemic circulation is small, anomalous pulmonary venous return can easily be missed both on oximetry and angiocardiography. Should this mishap occur then the patient may undergo a systemic-pulmonary shunt for low pulmonary blood flow and die from pulmonary oedema because of unrelieved obstructed total anomalous pulmonary venous drainage.

In addition to showing tracheal and bronchial anatomy, the filtered beam radiograph provides an opportunity of defining mediastinal structures which on the orthodox chest radiograph may be obscured by thymus, sternum, and spine. The absence of a main pulmonary artery conus may be noted in pulmonary atresia. In the central parts of the lung adjacent to the hilum, the position and calibre of vascular structures may be assessed. The size of the normally located left atrium may be inferred not only from the angle which the main bronchi form with each other, but also from the convexity of the lower margin of the left atrium. If the main bronchi are of narrow calibre, compression by vascular structures such as large pulmonary arteries may be suspected as a cause for tachypnoea, or even stridor and air trapping. One learns swiftly to identify on which side of the trachea the aortic arch lies from the radiograph.

In summary, the filtered beam radiograph supplants much of the need for tomography for the determination of bronchial situs, not only in patients with heart disease but also in patients with non-cardiac problems. By establishing bronchial situs, atrial situs can be predicted quickly and safely in the very young patient.

\section{References}

1 Liberthson RR, Hastreiter AR, Sinha SN, Bharati S, Novak GM, Lev $M$. Levocardia with visceral heterotaxy-isolated levocardia: pathologic anatomy and its clinical implications. Am Heart $\mathcal{F}$ 1973; 85: 40-54.

2 Lev M, Liberthson RR, Eckner FAO, Arcilla RA. Pathologic anatomy of dextrocardia and its clinical implications. Circulation 1968; 37: 979-99.

3 Lev M, Liberthson RR, Golden JG, Eckner FAO, Arcilla RA. The pathologic anatomy of mesocardia. Am f Cardiol 1971; 28: 428-35.

4 Ivemark BI. Implications of agenesis of the spleen on the pathogenesis of cono-truncus anomalies in childhood. Acta Paediatr Scand 1955; 44, suppl: 104.

5 Putschar WGJ, Manion WC. Congenital absence of the spleen and associated anomalies. Am $\mathcal{f}$ Clin Pathol 1956; 26: 429-70.

6 Ruttenberg HD, Neufeld HN, Lucas RV Jr, et al. Syndrome of congenital cardiac disease with asplenia: distinctive from other forms of congenital cyanotic cardiac disease. Am f Cardiol 1964; 13: 387-406.

7 Moller JH, Nakib A, Anderson RC, Edwards JE. Congenital cardiac disease associated with polysplenia. Circulation 1967; 36: 789-99. 
8 Van Mierop LHS, Gessner IH, Schiebler GL. Asplenia and polysplenia syndrome. In: Bergsma D, ed. Birth defects original article series. Vol VIII, No. 5. Congenital cardiac defects-recent advances. Baltimore. Williams \& Wilkins, 1972: 36-44.

9 Van Mierop LHS, Gessner IH, Schiebler GL. Asplenia and polysplenia syndrome. In: Bergsma $\mathrm{D}$, ed. Birth defects original article series. Vol III, No. 1. Congenital cardiac defects-recent advances. Baltimore: Williams \& Wilkins, 1972: 74-82.

10 Freedom RM. The asplenia syndrome: a review of significant extracardiac structural abnormalities in 29 necropsied patients. $\mathcal{F}$ Pediatr 1972; 81: 1130-3.

11 Rose V, Izukawa T, Möes CAF. Syndromes of asplenia and polysplenia. A review of cardiac and non-cardiac malformations in 60 cases with special reference to diagnosis and prognosis. $\mathrm{Br}$ Heart $\mathfrak{f}$ 1975; 37: 840-52.

12 Macartney FJ, Partridge JB, Shinebourne EA, Tynan MJ, Anderson RH. Identification of atrial situs. In: Anderson RH, Shinebourne EA, eds. Paediatric cardiology 1977. Edinburgh and London: Churchill Livingstone, 1978: 16-26.

13 Van Mierop LHS, Eisen S, Schiebler GL. The radiographic appearance of the tracheobronchial tree as an indicator of visceral situs. $\mathrm{Am} \mathcal{F} \mathrm{Cardiol}$ 1970; 26 : 432-7.

14 Stanger P. Rudolph AM, Edwards JE. Cardiac malpositions. An overview based on study of sixtyfive necropsy specimens. Circulation 1977; 56: 159-72.

15 Partridge JB, Scott O, Deverall PB, Macartney FJ. Visualisation and measurement of the main bronchi by tomography as an objective indicator of thoracic situs in congenital heart disease. Circulation 1975; 51: 188-96.

16 Dunbar JS. Upper respiratory tract obstruction in infants and children. Am $\mathcal{F}$ Roentgenol 1970; 109: 227-46.

17 Joseph PM, Berdon WE, Baker DH, Slovis TL, Haller JO. Upper airway obstruction in infants and small children. Radiology 1976; 121 : 143-8.

18 Wolf EL, Berdon WE, Baker DH. Improved plain film diagnosis of right aortic arch anomalies with high kilovoltage-selective filtration-magnification technique. Pediatr Radiol 1978; 7 : 141-6.
19 Soto B, Pacifico AD, Souza AS Jr, Bargeron LM Jr, Ermocilla R, Tonkin IL. Identification of thoracic isomerism from the plain chest radiograph. Am $\mathcal{F}$ Roentgenol 1978; 131: 995-1002.

20 Nie NH, Hull CH, Jenkins JG, Steinbrenner K, Bent DH. Statistical package for the social sciences. 2nd ed. New York: McGraw Hill, 1975.

21 Van Praagh R. The segmental approach to diagnosis in congenital heart disease. In Bergsma $\mathrm{D}$, ed. Birth defects original article series. Congenital cardiac defects-recent advances. Baltimore: Williams \& Wilkins, 1972: 4-23.

22 Van Praagh R, Van Praagh S, Vlad P, Keith JD. Anatomic types of congenital dextrocardia. Diagnostic and embryologic implications. Am $\mathcal{f}$ Cardiol 1964; 13 : 510-31.

23 Pernkopf E. Der partielle Situs inversus der Eingeweide beim Menschen. Gedanken zum Problem der Asymmetrie und zum Phannomen der Inversion. $Z$ Gesamte Anat 1926; 79: 577-752.

24 Van Mierop LHS, Wiglesworth FW. Isomerism of the cardiac atria in the asplenia syndrome. Lab Invest 1962; 11: 1303-15.

25 Landing BH, Lawrence TYK, Payne VC Jr, Wells TR. Bronchial anatomy in syndromes with abnormal visceral situs, abnormal spleen and congenital heart disease. Am F Cardiol 1971; 28: 456-62.

26 Brandt PWT, Calder AL. Cardiac connections: the segmental approach to radiologic diagnosis in congenital heart disease. Curr Probl Diagn Radiol 1977; 7: 1-35.

27 Caruso G, Becker AE. How to determine atrial situs? Considerations initiated by three cases of absent spleen with a discordant anatomy between bronchi and atria. Br Heart $\mathcal{F} 1979 ; 41$ : 559-67.

28 Macartney FJ, Zuberbuhler JR, Anderson RH. Morphologic considerations pertaining to the recognition of atrial isomerism-their consequences for sequential chamber localisation. $B r$ Heart $\mathcal{f} 1980$; in press.

Requests for reprints to Professor F J Macartney, The Hospital for Sick Children, Great Ormond Street, London WC1N 3JH. 